\title{
Health-related quality of life based on KIDSCREEN-52 in stuttering children and adolescents
}

\author{
Erdoğan ÖZGÜR', Börte GÜRBÜZ ÖZGÜR² \\ 1 Muğla Sitkı Koçman University, Medical Faculty, Department of Otorhinolaryngology, Muğla, Turkey \\ ORCID No: 0000-0002-5182-8831 \\ 2 Muğla Training and Research Hospital, Child and Adolescent Psychiatry Clinic, Muğla, Turkey \\ ORCID No: 0000-0002-9176-7359
}

\begin{abstract}
Objective: Stuttering is a communication disorder that can affect an individual's life in many ways. This study aimed to evaluate the effects of stuttering on children and adolescents' health-related quality of life (HRQoL).

Methods: This is a cross-sectional type of case-control study. Thirty-six children and adolescents diagnosed with stuttering according to DSM-5 and 37 age- and gender-matched healthy children and adolescents were included in the study. The child and adolescent's HRQoL in both groups was evaluated using the KIDSCREEN-52 self and proxy reports.
\end{abstract}

Results: No significant difference was observed in the physical well-being, psychological well-being, moods and emotions, self-perception, autonomy, parental relationships and home life, financial resources, social support and peers, school environment, social acceptance-bullying dimensions in the KIDSCREEN-52 questionnaire between-group comparison of both report and proxy results. The parental score reports were found to be statistically significantly lower than the children with stuttering in social acceptance-bullying dimension. In contrast, the children's scores in the dimensions of physical well-being, self-perception, parental relationships and home life, social support and peers and school environment were found to be statistically significantly lower than their parents.

Conclusion: According to the study results, it was observed that the HRQoL of children between the ages of 8-18 who stutter was not different from healthy children. Since factors affecting the HRQoL of children may be affected by developmental processes, the necessity of longitudinal assessment of the HRQoL of stuttering children should be considered.

Keywords: stuttering, childhood-onset speech fluency disorder, child, health-related quality of life, adolescent
Correspondence: Erdoğan Özgür

Department of Otorhinolaryngology, Mugla Sitki Kocman University Medical Faculty, Mugla, TURKEY

E-mail: erdoganozgur@mu.edu.tr
Online available at: www.entupdatesjournal.org 


\section{Introduction}

Stuttering is a disorder in the fluency and timing of speech that is not suitable for the person's age and language skills, can affect individuals of all ages, and often begins in childhood. Stuttering is characterized by stiffness in the flow of speech, inability to start speaking, prolonging the sound, pausing by repeating a sound, syllable, or word. ${ }^{[1]}$ Although the lifetime prevalence of stuttering is estimated to be between $0.3 \%$ and $1 \%$, its frequency in the preschool age group is estimated to be $5-10 \% .{ }^{[2,3]} 75-80 \%$ of the cases recover spontaneously 2-3 years after the onset. ${ }^{[4]}$ However, when stuttering is permanent, it can affect social and professional communication and general quality of life in adulthood. ${ }^{[5]}$ Stuttering is a multifactorial disorder that includes genetic, psychological, neurological, and behavioral features. Although $20-74 \%$ of studies have reported familial characteristics, the gene or mutation responsible for transmitting the disorder has not been shown. ${ }^{[6]}$

The term health-related quality of life (HRQoL) refers to a multidimensional evaluation of how many factors directly or indirectly related to health affect a person's overall functionality and well-being. ${ }^{[7]}$ Today, in evaluating the effects of a disease, objective or physician-oriented assessment methods are used, and the quality of life scales are used for patient-oriented assessment in treatment success or follow-up of the disease. It is essential to evaluate HRQoL, especially in chronic diseases and long-term treatments. ${ }^{[8]}$ One of the Diagnostic and Statistical Manual of Mental Disorders-5 (DSM-5) diagnostic criteria of childhood speech fluency disorder (stuttering) is limitations in effective communication, academic performance, social acceptance, job performance, and anxiety due to speech disorder. ${ }^{[1]}$ Considering this criterion, it can be thought that stuttering may negatively affect the quality of life of the person.

There are many studies in the literature on stuttering in the adult age group on quality of life. The majority of these studies reported that stuttering negatively affects the quality of life..$^{[9-12]}$ There are fewer studies covering childhood in this area. However, the results obtained from stuttering and HRQoL studies in children show differences. For ex- ample, studies conducted in the preschool age group have reported that stuttering has no adverse effects on HRQoL. ${ }^{[13,14]}$ While some studies argue that stuttering negatively affects HRQoL in school-age children, there are also studies arguing the opposite. ${ }^{[15,16]}$ Measurement tools such as EuroQoL EQ-VAS, The Child Health Questionnaire (CHQ), Infant and Toddler Quality of Life Questionnaire (ITQOL-97), and PedsQL were used in their studies. [14-16] The effectiveness of different self-report HRQoL assessment tools used in children was investigated. KIDSCREEN-52 and DCGM-37 were reported to be superior to other scales in understanding the needs of children. ${ }^{[17]}$ However, there is no study in the literature evaluating HRQoL associated with stuttering using KIDSCREEN or DCGM-37.

In this study, we aimed to evaluate the HRQoL of children and adolescents with stuttering using the KIDSCREEN-52 measurement tool and the parents' perception about their children's quality of life.

\section{Materials and Methods}

This is a cross-sectional case-control study. Approval was obtained from Muğla Sıtkı Koçman University Human Research Ethics Committee for the study. Written consent was obtained from the children participating in the study and from their parents. The study complied with the Helsinki Declaration.

\section{Sample and Data Collection}

A total of 40 stuttering children aged 8-18 and their parents who applied to the ENT and child and adolescent psychiatry outpatient clinic of Muğla Training and Research Hospital between February 2020 and March 2020 were included the study as a case group. Stuttering children newly diagnosed or with follow-up were included in the study in order of admission. Four children who did not fill out the scales were excluded and 36 were enrolled for the study. The diagnosis of stuttering was made according to DSM-5 by child and adolescent psychiatrist. ${ }^{[1]}$ The control group was chosen from those who applied to the ENT outpa- 
tient clinic. The control group consisted of 37 age and gender-matched healthy children who did not have any psychiatric or chronic diseases, including speech impairment and hearing loss, in their current examination or history. All children undergone ENT and hearing examination by an ENT/Audiology and Speech Disorders Specialist (first author) and mental state and intelligence examination by child and adolescent psychiatrist (second author). Only one of the children's parents filled out the questionnaire. The children filled in the KIDSCREEN-52 self-report and their parents the KIDSCREEN-52 proxy separately so that they could not see each other's questionnaires.

The exclusion criteria of this study were as follows: (i) patients with speech disorders other than stuttering, (ii) other psychiatric diagnoses (iii) patients with any medical illness received treatment, (iv) mental retardation, (v) chronic diseases, including speech impairment and hearing loss, in their current examination or history and (vi) children or parent who have not filled the scale totally.

Besides to exclude the effects of both COVID-19 and not attending the schools in Turkey due to the pandemic on quality of life, patients were excluded from the study after school closes.

\section{Data Collection Tools}

\section{Sociodemographic data form}

It is a data form prepared by researchers in which the participants' sociodemographic characteristics and variables related to stuttering are questioned.

\section{KIDSCREEN-52}

The scale was developed in a multi-center project with 13 European countries' participation to be used in epidemiological, public health, clinical research, and intervention studies in children. KIDSCREEN-52 is a general-purpose quality of life scale developed for children and adolescents aged 8-18. The scale, with its 52-question structure, questions children's quality of life in 10 different dimensions. These dimensions are physical well-being, psychological well-being, moods and emotions, self-perception, autono- my, parental relationships and home life, financial resources, social support and peers, school environment, social acceptance/bullying. In all KIDSCREEN questionnaires, items have a 5-point Likert-type response scale [(none, very little, moderate, more, and extremely) or (never, sometimes, often, very often and always)]. The score calculation is made on the T value, which is called the Rasch score for each dimension, and its average is converted as 50 , and the standard deviation is $10{ }^{[18,19]}$ It shows that the quality of life improves as the score increases. The Turkish validity and reliability study of the scale was conducted by Baydur et al. ${ }^{[20]}$ According to the validity and reliability study results, KIDSCREEN-52 confirmatory factor analysis fit index results were found to be good. Cronbach-alpha value was found between 0.69-0.90. Permission was obtained from Hakan Baydur and KIDSCREEN Group for the use of the questionnaire in this study.

\section{Statistical analysis}

The data were evaluated using the SPSS 23.0 (IBM) package program for Windows. Descriptive data were expressed as mean, standard deviation, number, percentage, minimum, maximum. The compliance of the data to normal distribution was evaluated with the Kolmogorov-Smirnov test. To compare KIDSCREEN-52 dimension scores between groups, the independent t-test from parametric tests or the Mann Whitney $U$ test from nonparametric tests were used. The relationship between KIDSCREEN-52 self and proxy dimension scores was analyzed using the Pearson correlation test. In the interpretation of the correlation coefficient, Cohen's (1988) classification was taken into consideration. ${ }^{[21]}$ Accordingly, $r=0-0.09$ no correlation, 0.10-0.29 low, 0.30-0.49 medium, 0.50-1 high level of correlation was accepted. For statistical significance, a p-value below 0.05 was considered significant.

\section{Results}

Thirty-six children diagnosed with stuttering and 37 healthy children as a control group was included in the study. Seventeen $(23.3 \%)$ of all children were girls, and $56(76.7 \%)$ were boys. There was no difference between 
the case and control groups regarding age and gender ( $\mathrm{p}>$ $0.05)$. The mean age of all participants was $10.67 \pm 2.82$ (min 7.5-max 17 years). The mean age of the case group was $10.81 \pm 2.96$; the control group's mean age was 10.54 \pm 2.71 years. The sociodemographic characteristics of the participants are given in Table 1. The mean initial age of children with stuttering was $5.06 \pm 1.57$. It was determined that $63.9 \%(\mathrm{n}=23)$ of these cases received speech therapy, $41.7 \%(\mathrm{n}=15)$ had a family history of stuttering and $27.8 \%(\mathrm{n}=10)$ had speech disorder accompanied by body movements.

No statistically significant difference was found in comparing both proxy and self-report questionnaire dimensions of the case and control groups (Table 2). According to the results of correlation analysis, the correlation coefficients between KIDSCREEN-52 self-report and proxy of the case group were $r=0.200$ for physical well-being dimension, $r=0.186$ for mood and affect dimension, $r=$ 0.192 for the parental relationships and home life dimension, $r=0.258$ for social support and peers dimension, $r=0.363$ for school environment dimension and $r=0.275$ for social acceptance-bullying dimension. When proxy and self-report KIDSCREEN-52 scores were compared in the case group, proxy scores in the dimensions of physical well-being, self-perception, parental relationships and home life, social support and peers and school environment were statistically significantly higher than self-report scores. In contrast, in the social acceptance-bullying dimension, self-report scores were statistically significantly higher than proxy scores (Figure 1).

\section{Discussion}

In this study, the health-related quality of life of 36 children between the ages of $8-18$ with a diagnosis of stuttering and 37 age-gender-matched healthy children was evaluated using KIDSCREEN-52. Besides, how the parents perceived their children's quality of life was evaluated using the KIDSCREEN-52 proxy. The mean age in the stuttering group was $10.81 \pm 2.96$ years. When the gender distribution of the cases was examined, it was found that the ratio of girls to boys was 1 to 3 . Studies have reported
Table 1. Sociodemographic characteristics of the children and their parents.

Case n (\%) Control n (\%)

Gender

$\begin{array}{lll}\text { Female } & 9(25) & 8(21.6) \\ \text { Male } & 27(75) & 29(78.4)\end{array}$

Educational status

Primary school

$19(52.8) \quad 19(51.4)$

Secondary school

$11(30.6) \quad 12(32.4)$

High school

$4(11.1)$

5 (13.5)

Open high school

$1(2.8)$

$1(2.7)$

Not going to school

$1(2.8)$

0

Maternal occupation

Housewife

$26(72.2) \quad 22(59.5)$

Working

9 (25) $15(40.5)$

Retired

$1(2.8)$

0

Father's occupation

Unemployed

1 (2.8)

$1(2.7)$

Working

$35(97.2)$

35 (94.6)

Retired

0

$1(2.7)$

Educational status of mother

Literate only

$1(2.8)$

0

Primary school

14 (38.9)

$15(40.5)$

Secondary School

9 (25)

10 (27)

High school

7 (19.4)

7 (18.9)

University

5 (13.9)

5 (13.5)

Father's education status

Primary school

$22(61.1)$

$19(51.4)$

Secondary school

$3(8.3)$

5 (13.5)

High School

9 (25)

10 (27)

University

2 (5.6)

$3(8.1)$

Marital status

$\begin{array}{lll}\text { Married } & 34(94.4) & 34(91.9) \\ \text { Divorced } & 2(5.6) & 3(8.1)\end{array}$

Family history of stuttering

$\begin{array}{lll}\text { Yes } & 15(41.7) & 2(5.4) \\ \text { No } & 21(58.3) & 35(94.6)\end{array}$


Table 2. Comparison of the dimensions of the KIDSCREEN-52 questionnaire between children with stuttering and their parents and the healthy control group.

\begin{tabular}{|c|c|c|c|}
\hline & Case $($ mean $\pm s d)$ & Control $($ mean $\pm s d)$ & $p$ \\
\hline \multicolumn{4}{|l|}{ Self-report } \\
\hline Physical well-being & $46.49 \pm 10.11$ & $50.44 \pm 8.67$ & 0.07 * \\
\hline Psychological well-being & $51.67 \pm 11.15$ & $51.54 \pm 8.63$ & $0.89 *$ \\
\hline Mood and emotions & $50.28 \pm 12.69$ & $49.9 \pm 9.73$ & $0.88^{\#}$ \\
\hline Self-perception & $52.26 \pm 10.21$ & $51.09 \pm 8.12$ & $0.58^{*}$ \\
\hline Autonomy & $54.59 \pm 11.07$ & $52.83 \pm 9.66$ & 0.57 * \\
\hline Parental relationships and home life & $49.33 \pm 11.17$ & $49.93 \pm 13.53$ & $0.98^{*}$ \\
\hline Financial resources & $51.72 \pm 10.64$ & $48.49 \pm 10.22$ & $0.18^{\#}$ \\
\hline Social support and peers & $47.6 \pm 10.94$ & $48.68 \pm 12.53$ & 0.77 * \\
\hline School environment & $49.18 \pm 10.14$ & $47.95 \pm 10.4$ & 0.44 * \\
\hline Social acceptance-bullying & $57.94 \pm 12.15$ & $56.07 \pm 11.11$ & 0.49 * \\
\hline \multicolumn{4}{|l|}{ Proxy } \\
\hline Physical well-being & $52.36 \pm 11.76$ & $53.41 \pm 10.38$ & $0.88^{*}$ \\
\hline Psychological well-being & $53.3 \pm 13.73$ & $53.28 \pm 10.87$ & 0.67 * \\
\hline Mood and emotions & $53.88 \pm 12.04$ & $57.77 \pm 7.88$ & $0.11^{\#}$ \\
\hline Self-perception & $56.91 \pm 12.81$ & $59.63 \pm 11.25$ & 0.34 * \\
\hline Autonomy & $51.08 \pm 12.76$ & $49.06 \pm 10.64$ & $0.5^{*}$ \\
\hline Parental relationships and home life & $54.08 \pm 13.79$ & $51.24 \pm 11.38$ & $0.23 *$ \\
\hline Financial resources & $51.12 \pm 12.12$ & $50.29 \pm 10.33$ & $0.75^{\#}$ \\
\hline Social support and peers & $53.52 \pm 11.62$ & $49.99 \pm 12.62$ & $0.22^{\#}$ \\
\hline School environment & $55.89 \pm 14.07$ & $54.07 \pm 12.85$ & $0.44 *$ \\
\hline Social acceptance-bullying & $47.67 \pm 8.03$ & $49.48 \pm 8.35$ & $0.44 *$ \\
\hline
\end{tabular}

* Mann Whitney U test, " Independent group t test

that stuttering is 2-3 times more common in boys than in girls. ${ }^{[22,23]}$ The majority of the children in the study were of primary and secondary school age.

According to the results of the present study, no significant difference was observed in the physical well-being, psychological well-being, moods and emotions, self-perception, autonomy, parental relationships and home life, financial resources, social support and peers, school environment, social acceptance-bullying dimensions in the KIDSCREEN-52 questionnaire between groups in both 
self-report $\square$ proxy

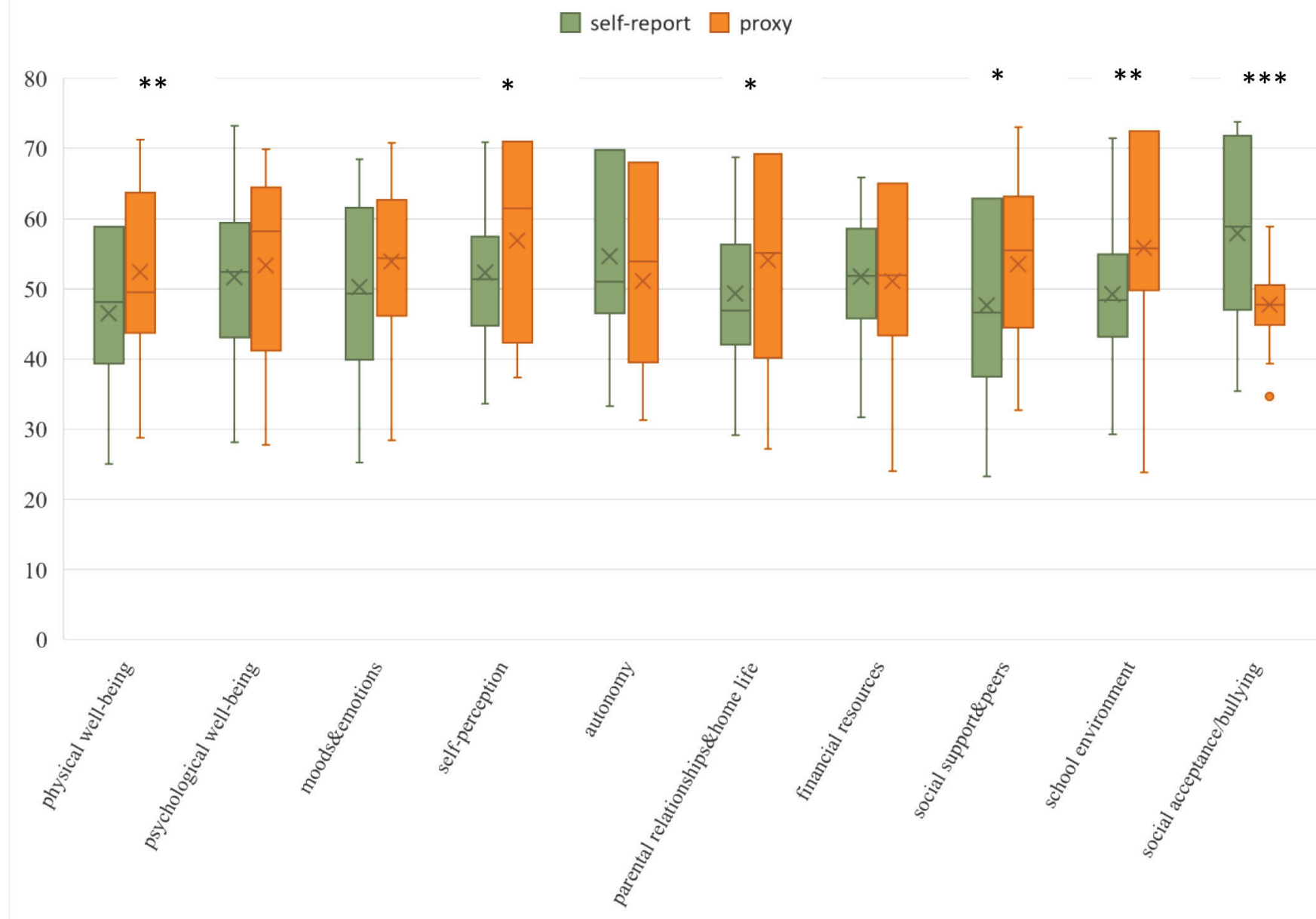

Figure 1. Comparison of KIDSCREEN-52 self-report and proxy questionnaire dimensions of the group with stuttering (Mann Whitney $U$ test, * $p<0.05, * * p<0.01, * * * p<0.001$ )

self-report and proxy. Although it is thought that stuttering can affect a person's life in many ways, studies have given conflicting results on HRQoL in children. Reilly et al. and de Sonneville-Koedoot et al., like our results, observed that there was no negative effect in the HRQoL evaluations of preschool children with stuttering. ${ }^{[13,14]}$ Chun et al. evaluated the disease-specific HRQoL in children between the ages of 7-12 and reported that there was a moderate negative impact. ${ }^{[15]}$ On the other hand, when Doğan et al. evaluated school-age stuttering children's quality of life using the Pediatric Quality of Life Inventory, they found a negative influence in all dimensions. ${ }^{[16]}$ In the limited number of studies in the literature, evaluating the quality of life of stuttering children by using different measurement tools causes difficulties in comparing these studies' results.
In our study, no negative effects were found in dimensions of psychological well-being, moods and emotions, and self-perception in those with stuttering. However, some studies report that psychological problems such as depression and anxiety may accompany especially in adults. ${ }^{[24]}$ On the other hand, different results have been reported on anxiety symptoms in studies conducted on children. Anxiety level in children with stuttering in preschool age group $^{[25]}$ and ages between 9-14 ${ }^{[26]}$ was not different from the control group. Messenger et al. reported that the anxiety levels of 73 school-age children and adolescents with stuttering were within normal limits. ${ }^{[27]}$ Although our study did not measure the psychological symptom severity, the psychological dimension results are consistent with the literature. 
The last two dimensions of the KIDSCREEN-52 scale, school environment and social acceptance-bullying, investigate children's relationships between school and friends and the effect of peer bullying on children's quality of life. In our study, when we compared groups, we found no significant difference in these areas. However, parents scored that their children's quality of life was worse in the social acceptance-bullying domain. Studies have reported that children with stuttering are exposed to peer bullying. According to a study conducted in the UK, a significant majority ( $82 \%$ ) of a group of 324 stuttering children reported being bullied at some point in their school life. They emphasized that the age group most exposed to peer bullying is between 11 and 13 years old. ${ }^{[28]}$ Solberg and Olweus reported that $80 \%$ of adults with stuttering were exposed to peer bullying in childhood. ${ }^{[29]}$ In a retrospective study of stuttering effects on school life in adults with stuttering, the participants reported that stuttering had extremely harmful effects throughout school life and had long-term effects on social and emotional functioning. ${ }^{[12]}$ In our study, although the quality of life scores of the stuttering group in the social acceptance-bullying dimension are not different from the control group, children's perceptions may change in the longitudinal follow-up. Although the quality of life does not deteriorate in terms of social acceptance or peer bullying in childhood, mainly due to the risk of early adolescence in terms of exposure to peer bullying in stuttering children, it is necessary to evaluate children who stutter at different age periods from this perspective.

There was no difference in parental relationships and home life dimensions of children with stuttering compared to the control group. Bodur et al. reported that parental attitudes of children with stutter differ significantly from those without stuttering. ${ }^{[30]}$ Adriaensens et al. reported that adolescents with stuttering families experience high levels of emotional tension, family conflict, and difficulty in managing their children's frustration. ${ }^{[31]}$ Parents of preschool children with stuttering declared that their children were adversely affected by stuttering in some areas, but their quality of life was not generally affected. ${ }^{[32]}$ However, little is known about the study of how parents feel because of their child's stuttering and how this affects domestic relationships.

One of the striking results of our study is the determination of a significant difference and a low-moderate correlation in some dimensions between self-report and proxy. It has been reported that the agreement between KIDSCREEN's self-report and proxy results varies depending on the country, there is consensus in physical and cognitive areas, and there is inconsistency in social and psychological areas. ${ }^{[33]}$ Baydur et al. found some inconsistencies in self-report and proxy evaluations in different Turkish versions of KIDSCREEN. ${ }^{[34]}$ The differences between self-report and proxy notifications in our study may be due to cultural adaptation or the difference in perception of stuttering in children and their proxy. Studies addressing consensus or discrepancies between notifications are needed.

Strength of the study is being the first study conducted using the KIDSCREEN-52 scale, which evaluates the quality of life in a wide range according to many scales used to evaluate HRQoL in children. Lack of disease-specific HRQoL is one of the limitations of this study. However, there is no specific questionnaire for stuttering, which is valid and reliable in Turkish. Results of the study may not be generalizable due to the small number of study groups and only the inclusion of hospital admissions. Besides, non-homogenous age group and small number of female gender can be considered as limitations.

\section{Conclusion}

As a result, it has been observed that the HRQoL of children with stuttering between the ages of 8-18 is not different from healthy children. It should be kept in mind that the effects of stuttering may occur at different age periods. There is a need for studies that examine the effects of variables such as coping with this disorder, speech therapy and treatment processes, psychological support, stuttering severity, and stuttering characteristics on children's quality of life.

\section{Acknowledgements: None}


Ethics Committee Approval: The study protocol was approved by the local ethics committee $(200018 / 31)$

Informed Consent: Written informed consent was obtained from the patients who had participated in this study.

\section{References}

1. American Psychiatric Association., American Psychiatric Association. DSM-5 Task Force. Diagnostic and statistical manual of mental disorders : DSM-5. 5th ed. Washington, D.C.: American Psychiatric Association; 2013. p. xliv, 947 p.

2. Mansson H. Childhood stuttering: Incidence and development. Journal of Fluency Disorders 2000;25(1):47-57.

3. McKinnon DH, McLeod S, Reilly S. The prevalence of stuttering, voice, and speech-sound disorders in primary school students in Australia. Lang Speech Hear Serv Sch 2007;38(1):5-15. doi: 10.1044/0161-1461(2007/002)

4. Kefalianos E, Onslow M, Packman A, et al. The History of Stuttering by 7 Years of Age: Follow-Up of a Prospective Community Cohort. J Speech Lang Hear Res 2017;60(10):2828-39. doi: 10.1044/2017_ JSLHR-S-16-0205

5. Beilby JM, Byrnes ML, Meagher EL, Yaruss JS. The impact of stuttering on adults who stutter and their partners. J Fluency Disord 2013;38(1):1429. doi: 10.1016/j.jfludis.2012.12.001

6. Smith A, Weber C. How Stuttering Develops: The Multifactorial Dynamic Pathways Theory. J Speech Lang Hear Res 2017;60(9):2483-505. doi: 10.1044/2017_JSLHR-S-16-0343

7. Ebrahim S. Clinical and public health perspectives and applications of health-related quality of life measurement. Soc Sci Med 1995;41(10):138394. doi: 10.1016/0277-9536(95)00116-o

8. Hays RD, Reeve BB. Measurement and modeling of health-related quality of life. In: Killewo J, Heggenhougen HK, Quah SR, editors. Epidemiology and demography in public health. 1 ed. San Diego: Academic Press; 2010. p. 195-205.

9. Craig A, Blumgart E, Tran Y. The impact of stuttering on the quality of life in adults who stutter. J Fluency Disord 2009;34(2):61-71. doi: 10.1016/j. jfludis.2009.05.002

10. Koedoot C, Bouwmans C, Franken MC, Stolk E. Quality of life in adults who stutter. J Commun Disord 2011;44(4):429-43. doi: 10.1016/j.jcomdis.2011.02.002

11. Klompas M, Ross E. Life experiences of people who stutter, and the per-
Author Contributions: Designing the study - E.Ö., B.G.Ö., Collecting the data - E.Ö., B.G.Ö.; Analysing the data - E.Ö., B.G.Ö.; Writing the manuscript - E.Ö., B.G.Ö.; Confirming the accuracy of the data and the anal-yses - E.Ö., B.G.Ö.

Conflict of Interest: The authors have no conflicts of interest to declare.

Financial Disclosure: The authors declare that this study has not received any financial support.

ceived impact of stuttering on quality of life: personal accounts of South African individuals. J Fluency Disord 2004;29(4):275-305. doi: 10.1016/j. jfludis.2004.10.001

12. Hayhow R, Cray AM, Enderby P. Stammering and therapy views of people who stammer. J Fluency Disord 2002;27(1):1-16; quiz -7. doi: 10.1016/ s0094-730x(01)00102-4

13. Reilly S, Onslow M, Packman A, et al. Natural history of stuttering to 4 years of age: a prospective community-based study. Pediatrics 2013;132(3):4607. doi: 10.1542/peds.2012-3067

14. de Sonneville-Koedoot C, Stolk EA, Raat H, Bouwmans-Frijters C, Franken MC. Health-related quality of life of preschool children who stutter. J Fluency Disord 2014;42:1-12. doi: 10.1016/j.jfludis.2014.09.001

15. Chun RY, Mendes CD, Yaruss JS, Quesal RW. The impact of stuttering on quality of life of children and adolescents. Pro Fono 2010;22(4):567-9. doi: 10.1590/s0104-56872010000400035

16. Doğan M, Nemli N, Bayram A, Kaya A, Yaşar M. Findings of quality of life in children with stuttering. Praxis of ORL 2016;4(2):64-9. doi: 10.5606/ kbbu.2016.93063

17. Petersson C, Simeonsson RJ, Enskar K, Huus K. Comparing children's self-report instruments for health-related quality of life using the International Classification of Functioning, Disability and Health for Children and Youth (ICF-CY). Health Qual Life Outcomes 2013;11:75. doi: 10.1186/1477-7525-11-75

18. Ravens-Sieberer U, Gosch A, Rajmil L, et al. KIDSCREEN-52 quality-of-life measure for children and adolescents. Expert Rev Pharmacoecon Outcomes Res 2005;5(3):353-64. doi: 10.1586/14737167.5.3.353

19. Europe TKG. The KIDSCREEN Questionnaires - Quality of life questionnaires for children and adolescents. Handbook. Lengerich: Pabst Science Publishers; 2006. p.

20. Baydur H, Ergin D, Gerçeklioğlu G, Eser E. Reliability and validity study of the KIDSCREEN Health-Related Quality of Life Questionnaire in a Turkish child/adolescent population. Anatolian Journal of Psychiatry 2016;17(6):496-505. doi: 0.5455/apd.214559 
21. Cohen J. Statistical power analysis for the behavioral sciences. 2nd ed. Hillsdale, N.J.: L. Erlbaum Associates; 1988. p. xxi, 567 p.

22. Gürbüz-Özgür B, Özgür E. An Analysis of Sociodemographic and Clinical Characteristics in Children and Adolescents Diagnosed with Childhood Onset Speech Fluency Disorder. ENT Updates 2019;9(3):185-90. doi: 0.32448/entupdates.610265

23. Baker BM, Blackwell PB. Identification and remediation of pediatric fluency and voice disorders. J Pediatr Health Care 2004;18(2):87-94. doi: 10.1016/j.pedhc.2003.09.008

24. Tran Y, Blumgart E, Craig A. Subjective distress associated with chronic stuttering. J Fluency Disord 2011;36(1):17-26. doi: 10.1016/j.jfludis. 2010.12 .003

25. Yairi E, Ambrose NG. Early childhood stuttering I: persistency and recovery rates. J Speech Lang Hear Res 1999;42(5):1097-112. doi: 10.1044/ jslhr.4205.1097

26. Craig A, Hancock K. Anxiety in Children and Young Adolescents who Stutter. Australian Journal of Human Communication Disorders 1996;24(1):28-38. doi: 10.3109/as12.1996.24.issue-1.04

27. Messenger M, Packman A, Onslow M, Menzies R, O’Brian S. Children and adolescents who stutter: Further investigation of anxiety. J Fluency Disord 2015;46:15-23. doi: 10.1016/j.jfludis.2015.07.006

28. Mooney S, Smith PK. Bullying and the Child who Stammers. BJSE 1995;22(1):24-7. doi: 10.1111/j.1467-8578.1995.tb00907.x
29. Solberg ME, Olweus D. Prevalence estimation of school bullying with the Olweus Bully/Victim Questionnaire. Aggr Behav 2003;29(3):239-68. doi: https://doi.org/10.1002/ab.10047

30. Bodur S, Tas-Torun Y, Gül H, et al. Parental attitudes in children with persistent developmental stuttering: a case-control study. Arch Clin Psychiatry 2019;46(4):103-6. doi: 10.1590/0101-60830000000204

31. Adriaensens S, Beyers W, Struyf E. Impact of stuttering severity on adolescents' domain-specific and general self-esteem through cognitive and emotional mediating processes. J Commun Disord 2015;58:43-57. doi: 10.1016/j.jcomdis.2015.10.003

32. Langevin M, Packman A, Onslow M. Parent perceptions of the impact of stuttering on their preschoolers and themselves. J Commun Disord 2010;43(5):407-23. doi: 10.1016/j.jcomdis.2010.05.003

33. Robitail S, Simeoni MC, Ravens-Sieberer U, Bruil J, Auquier P, Group K. Children proxies' quality-of-life agreement depended on the country using the European KIDSCREEN-52 questionnaire. J Clin Epidemiol 2007;60(5):469-78. doi: 10.1016/j.jclinepi.2006.09.007

34. Baydur H, Ergin D, Gerçeklioğlu G, Eser E. Comparison of the self and the proxy versions of the KIDSCREEN quality of life scale: To what extend can parents predict quality of life of their children? İzmir Dr Behçet Uz Çocuk Hast Dergisi 2016;6(1):15-24. doi: 10.5222/buchd.2016.015

This is an open access article distributed under the terms of the Creative Commons Attribution-NonCommercial-NoDerivs 3.0 Unported (CC BY- NC-ND3.0) Licence (http://creativecommons.org/licenses/by-nc-nd/3.0/) which permits unrestricted noncommercial use, distribution, and reproduc- tion in any medium, provided the original work is properly cited.

Please cite this article as: Özgür E., Gürbüz Özgür B. Health-related quality of life based on KIDSCREEN-52 in stuttering children and adolescents. ENT Updates 2020;10(3): 430-438 